\title{
Role of Helicobacter pylori Infection in Recurrent Abdominal Pain of the Child in Brazzaville
}

\author{
Ollandzobo Ikobo Lucie Charlotte ${ }^{1,2}$, Ahombo Niotsebe Lydie Bénédicte1, \\ Mongo-Onkouo Arnaud 1,3, Ahoui Apendi Clausina Rochelvie ${ }^{1,3}$, Itoua Ngaporo Ngala Akoa1,3, \\ Mimiesse Mounanou Jile Florent ${ }^{1,3}$, Tchidjo Ngamo Lynda ${ }^{1}$, Déby Gassaye ${ }^{1,3}$, \\ Mabiala Babela Jean Robert ${ }^{1,2}$, Atipo Ibara Blaise Irénée ${ }^{1,3}$, Ibara Jean-Rosaire ${ }^{1,3}$ \\ ${ }^{1}$ Faculty of Health Sciences, Marien Ngouabi University of Brazzaville, Brazzaville, Congo \\ ${ }^{2}$ Infants Pediatric ward, Brazzaville University Teaching Hospital, Brazzaville, Congo \\ ${ }^{3}$ Gastroentérology and Internal Medicine Ward, Brazzaville University Teaching Hospital, Brazzaville, Congo \\ Email: lucieatipo@hotmail.fr
}

How to cite this paper: Charlotte, O.I.L., Bénédicte, A.N.L., Arnaud, M.-O., Rochelvie, A.A.C., Akoa, I.N.N., Florent, M.M.J., Lynda, T.N., Gassaye, D., Robert, M.B.J., Irénée, A.I.B. and Jean-Rosaire, I. (2020) Role of Helicobacter pylori Infection in Recurrent Abdominal Pain of the Child in Brazzaville. Open Journal of Pediatrics, 10, 587-599.

https://doi.org/10.4236/ojped.2020.104060

Received: August 18, 2020

Accepted: November 2, 2020

Published: November 5, 2020

Copyright $\odot 2020$ by author(s) and Scientific Research Publishing Inc. This work is licensed under the Creative Commons Attribution International License (CC BY 4.0).

http://creativecommons.org/licenses/by/4.0/ (c) (i) Open Access

\begin{abstract}
The Helicobacter pylori $(\mathrm{Hp})$ infection is a public health problem, especially in developing countries. However, the responsibility of Hp for the occurrence of recurrent abdominal pain is still unclear. Objectives: To determine the prevalence of Helicobacter pylori $(\mathrm{Hp})$ infection in children with recurrent abdominal pain (RAP) in Brazzaville and to establish the relationship between Hp infection and RAP. Patients and Methods: We conducted a cross-sectional case-control study, between March and September 2018, including 106 children with RAP and 218 children without RAP, aged 2 to 17 years old, received in health centres in Brazzaville. All the children were subjected to detection of $\mathrm{Hp}$ fecal antigen by qualitative immuno-chromatography in the faeces. Results: The prevalence of $\mathrm{Hp}$ infection among children with RAP in Brazzaville was $43.4 \%$. The female sex was most represented in both populations, with a sex ratio of 0.84 in the infected population. Compared with controls, these were children with a mean age of $8.13 \pm 4.57$ years. Infected children with RAP were unschooled in $66.7 \%(\mathrm{n}=31)$ of cases $(\mathrm{p}<$ $0.05)$. Those using potty were $63 \%(n=29)$. Handwashing before meals and after using the toilet was not done in $66.7 \%(\mathrm{n}=31)$ and $56.5 \%(\mathrm{n}=26)$ of cases, respectively. The proportions were almost similar in the control population. The epigastric site of pain was found in $51.8 \%$ of children infected with RAP, the association between Hp infection and the site of pain was statistically significant $(\mathrm{p}=0.009)$. The epidemiological factors influencing Hp infestation in children were identical in both groups, those factors were: age
\end{abstract}


$(\mathrm{OR}=0.61 ; \mathrm{p}<0.04)$, education level $(\mathrm{OR}=0.35 ; \mathrm{p}<0.01)$ of the children and guardian's age $(\mathrm{OR}=1.22 ; \mathrm{p}<0.03)$, type of toilet $(\mathrm{OR}=2.37 ; \mathrm{p}<0.02)$ and hand washing $(\mathrm{OR}=1 ; \mathrm{p}<0.01)$. No statistically significant association was found between Hp infection and RAP ( $p=0.10)$. Conclusion: Hp infection is common among children with RAP in Brazzaville. It is favoured by young age and lack of hygiene. The cause and effect relationship between $\mathrm{Hp}$ and RAP has not been found. Nevertheless, the search for Hp fecal antigen in children with RAP should be recommended in order to improve the management of this pathology.

\section{Keywords}

Helicobacter pylori, Recurrent Abdominal Pain, Fecal Antigen, Child, Brazzaville

\section{Introduction}

Helicobacter pylori $(\mathrm{Hp})$ infection is caused by a gram-negative, microaerophilic, spiral and helical shape bacterium of the genus Helicobacter with genomic diversity [1]. It is a public health problem, especially in developing countries [2] [2]. Prevalence varies between $1 \%$ and $30 \%$ in developed countries [4], however in sub-Saharan African countries including Congo, prevalence is over $40 \%$ in paediatric populations [5] [6] [7] [8]. Contamination is essentially oral-oral or fecal-oral in childhood. The bacterium colonises the gastric mucosa for a long time and causes acute, even chronic inflammation, which is responsible for various clinical manifestations, some of which have a very serious evolution towards peptic ulcer or gastric cancer [1] [4] [9]. The diagnosis of Hp infection is easy in children and is based preferably on the search for Hp monoclonal antigens (Ag) in the stool [10] [11]. Recurrent abdominal pain (RAP) is frequently observed in children in the range of $40 \%-90 \%$ [12]. However, the responsibility of $\mathrm{Hp}$ for the occurrence of recurrent abdominal pain is still unclear, despite the fact that some authors believe that the presence of CagA+ strain may be responsible for the recurrent abdominal pain in infected children [13]. Assuming that precariousness is an important predictive factor, and that the RAPs are due to a high Hp infestation, it is likely that the presence of the Cytoxin associated gene A (CagA) strain would be the cause of the RAP in infected children [14]. We proposed to carry out this work, the main objective of which is to improve the management of childhood RAP in Brazzaville, more specifically, to determine the prevalence of $\mathrm{Hp}$ infection in children with RAP in Brazzaville, to identify the factors influencing the occurrence of infection in these children and to establish the relationship between $\mathrm{Hp}$ infection and RAP.

\section{Patients and Methods}

We conducted a cross-sectional case-control study, between March and Sep- 
tember 2018, i.e. 7 months in the paediatric wards of Brazzaville hospitals, including the hospital teaching university, the Pierre Mobengo Central Army Hospital, the Base Hospital of Makelekelé, the Talangai Reference Hospital, the Marien Ngouabi Paediatric Hospital, and the Sino-Congolese Friendship Hospital of M'Filou. The study population consisted of all children seen for RAP in the centres selected for the study (case population) and children without RAP (control population) during the study period.

In the case population, we included children aged between 2 and 17 years old, presenting with RAP, that is at least three episodes of abdominal pain during a 3 month period, with an intensity that interferes with the child's everyday life and activity. We did not include children with abdominal pain related to a known pathology for which they were being monitored. In the control population, children with the same age group were included. Children with abdominal pain syndrome and those who had been on proton pump inhibitors, antisecretory agents and antibiotics for at least one month were not included in the study. Informed consent from guardians was mandatory for all children selected. We obtained the consent from the ethics committee for health sciences research in Congo (decision $\left.n^{\circ} 062 / M R S I T / I R S S A / C E R S S A\right)$, prior to the study. The children were systematically enrolled as they were screened following a triple epidemiological, clinical and etiological investigation, which enabled us to obtain, after matching one case of RAP for two controls, a consecutive sample of 318 children divided into two groups. Group 1 (cases: 106 children with RAP) and group 2 (controls: 212 children without RAP). Data were collected on a pre-determined survey sheet. The study variables were sociodemographic (sex, age, education, household size and socio-economic level of the family), lifestyle (type of toilet, water source, hand washing before and after meals and after using the toilet), clinical (location and type of abdominal pain, associated signs such as vomiting, signs of gastroesophageal reflux disease, gastrointestinal haemorrhage) and biological (detection of $\mathrm{Hp}$ monoclonal Ag in fresh stools). We defined the latrine as a pit dug in loose soil, without a drainage system, covered either by an assembly of branches or by a concrete slab centred by a hole for the passage of excreta. The modern toilet is a sanitary facility with a flushing or siphon system to evacuate excreta into a septic tank. The chamber pot, commonly known as a potty, is a container with or without a lid on which the child sits to relieve himself or herself and then the contents are emptied into the toilet. We have considered tap water as a source of water, which is generally potable because it is regulated by the national water company. It becomes private tap water when it is distributed directly to a household or public tap water when it is available to a large number of households; well water, which is non-potable water, rises to ground level by means of a bucket or manual pump; spring water meets the same requirements as natural water, with the difference that its mineral salt and trace element content is not stable. Fresh faeces was defined as freshly emitted faecal matter, collected in a fixed booth at the survey site, without any preparation, and sent to the laboratory up to one hour after the end of the collection, away from excessive 
heat. Sometimes the faeces were kept in a cool place between $2^{\circ} \mathrm{C}$ and $8^{\circ} \mathrm{C}$ for 48 hours before analysis. The search for Hp monoclonal Ag was carried out in fresh faeces using strips of the CerTestR H. Pylori rapid diagnostic test (RDT) based on the principle of immuno-chromatography. The judgement criteria were the detection of fecal Hp Ag by the presence of one (negative result) or two (positive result) lines on the RDT strip.

Data were captured and processed using CS pro Version 7.1, SPSS 21 and Microsoft Excel 2016. Qualitative variables were presented in numbers and percentages in parentheses. Quantitative variables were expressed as mean \pm standard deviation. The comparison of qualitative variables used Pearson's chi-square test, while the comparison of quantitative variables used Student's t-test. A bivariate analysis established the correlation between the dependent variable (health phenomenon studied) and the presence of certain factors (independent variable) with calculation of odds ratio (OR) and with $95 \%$ confidence intervals derived using the test-based method. (In most situations, the odds ratio provides a good approximation of the relative risk, i.e., the risk of recurrent abdominal pain in children with $\mathrm{H}$ pylori infection, compared with the risk in uninfected children). For the comparisons, the significance threshold was $<0.05$.

\section{Results}

Out of a total of 318 cases, 106 children included had RAP, of which 64 cases (60.4\%) were girls and 42 cases (39.6\%) boys; in 46 of these cases, the Hp fecal Ag test was positive, thus a prevalence of $43.4 \%(46 / 106)$. In contrast, the prevalence of $\mathrm{Hp}$ in children without RAP was $35.8 \%$ (76/212). Females were most represented in both populations, with a sex ratio of 0.84 in the infected population with RAP and 0.49 in the population of infected children without RAP (139/212). The mean age of infected children with RAP was $8.13 \pm 4.57$ years (extremes: 2 and 17 years) and those under 5 years of age accounted for $57.1 \%(\mathrm{p}$ $<0.05)$. Infected children with RAP were unschooled in $66.7 \%(\mathrm{n}=31)$ of cases $(\mathrm{p}<0.05)$ and lived in a $1-4$ persons household in $53.8 \%$ of cases; the average household size was $6.33 \pm 2.38$ persons (extremes: 2 and 11$)(\mathrm{p}<0.05)$. Compared to controls, the average age of children was $8.34 \pm 4.63$ years, $48.9 \%$ were unschooled $(\mathrm{p}=0.05)$ and $47.1 \%$ lived in a household of $2-4$ people (extremes of 2 and 13). The average age of guardians of infected children with RAP was $42.09 \pm 8.89$ years (extremes: 24 and 64 years). Children with guardians aged 35 - 44 years accounted for $52.4 \%(\mathrm{n}=22 ; \mathrm{P}=0.03)$; while in the control population it was $40.53 \pm 11.08$ (extremes: 17 and 66 years) and for 29 (46.8\%) of the children the parents were younger than 35 years of age $(\mathrm{P}<0.04)$. In the case population, the children belonged to a family of average socio-economic level ( $\mathrm{n}$ $=71)$, i.e. $66.7 \%$, low $(45)$, i.e. $42 \%$, and high $(\mathrm{n}=21)$, i.e. $20 \%$. They were of low socio-economic level $(\mathrm{n}=88)(41.3 \%)$, medium $(\mathrm{n}=72)(33.9 \%)$ and high $(\mathrm{n}=$ 27) (12.5\%) among the controls. The distribution of children according to lifestyle habits in the two populations is recorded in Table 1 and Table 2 (variables are expressed in numbers and percentages in brackets). After logistic regression, 
the factors influencing the acquisition of $\mathrm{Hp}$ infection in children with RAP are shown in Table 3. Clinically, constant abdominal pain in all infected children was epigastric $(51.8 \%)$, periumbilical $(40.7 \%)$ or diffuse $(40 \%)$, rarely hypochondrial. A type of burn (58.6\%), cramping (48.3\%), unspecified (36.4\%) and compressive (26.9\%). Among the associated signs, nausea and vomiting were observed in $39(54.1 \%)$ children with $\mathrm{p}<0.03$, hematemesis in 3 children $(60 \%)$, melena in 2 children (66.7\%), early satiety in 5 children (55.6\%), gastric fullness in 4 children (57.1\%), eructation in 3 cases (42.9\%) and pyrosis in 1 (50\%) case. Table 4 shows the results of the bivariate analysis between the case and control populations.

Table 1. Lifestyle patterns of children with RAP with fecal HpAg positive (cases).

\begin{tabular}{|c|c|c|c|c|c|}
\hline & Facteurs & Positive (n; \%) & Negative $(n ; \%)$ & OR $(95 \%)$ & $\mathbf{P}$ \\
\hline \multicolumn{6}{|c|}{ Type of toilets } \\
\hline- & Modern toilet & $12(25)$ & $45(75)$ & $0.30(0.14-0.64)$ & $<0.001$ \\
\hline- & Pit toilet & $20(44.2)$ & $33(55.8)$ & $1(0.51-1.97)$ & $<0.98$ \\
\hline- & Chamber pot & $29(62.5)$ & $23(37.5)$ & $3.07(1.54-6.09)$ & $<0.001$ \\
\hline \multicolumn{6}{|c|}{ Water source } \\
\hline- & Public tap & $22(47.5)$ & $32(52.5)$ & $1.31(0.69-2.47)$ & $<0.40$ \\
\hline- & Private tap & $17(37.5)$ & $38(62.5)$ & $0.80(0.41-1.54)$ & $<0.51$ \\
\hline- & Spring water & $20(42.9)$ & $34(57.1)$ & $1.09(0.57-2.07)$ & $<0.78$ \\
\hline- & Well & $18(40)$ & $36(60)$ & $0.88(0.46-1.68)$ & $<0.70$ \\
\hline \multicolumn{6}{|c|}{ Hand washing } \\
\hline- & Before meal & $18(38.6)$ & $37(61.4)$ & $0.31(0.14-0.69)$ & $<0.004$ \\
\hline- & After meal & $18(39.8)$ & $36(60.2)$ & $0.28(0.12-0.63)$ & $<0.002$ \\
\hline & After toilet & $15(33.3)$ & $40(66.7)$ & $0.37(0.16-0.83)$ & $<0.016$ \\
\hline
\end{tabular}

Table 2. Lifestyle patterns of children without RAP with fecal HpAg positive (controls).

\begin{tabular}{|c|c|c|c|c|c|}
\hline & Factors & Positive (n; \%) & Negative (n; \%) & OR (IC: 95\%) & $\mathbf{P}$ \\
\hline \multicolumn{6}{|c|}{ Type of toilet } \\
\hline- & Modern toilet & $19(25.4)$ & $101(74.6)$ & $0.37(0.21-0.65)$ & $<0.0007$ \\
\hline- & Latrine & $29(38.1)$ & $84(61.9)$ & $0.89(0.53-1.48)$ & $<0.65$ \\
\hline- & Chamber pot & $43(56.5)$ & $59(43.5)$ & $2(1.69-4.65)$ & $<0.0001$ \\
\hline \multicolumn{6}{|c|}{ Water source } \\
\hline- & Public tap & $32(41.6)$ & $79(58.4)$ & $2.07(1.26-3.40)$ & $<0.004$ \\
\hline- & Private tap & $24(31.7)$ & $93(68.3)$ & $1.10(0.65-1.86)$ & $<0.69$ \\
\hline- & Spring & $17(22.2)$ & $105(77.8)$ & $0.60(0.34-1.07)$ & $<0.08$ \\
\hline- & Well & $18(23.5)$ & $104(76.5)$ & $0.65(0.37-1.15)$ & $<0.14$ \\
\hline \multicolumn{6}{|c|}{ Hand washing } \\
\hline- & Before meal & $24(31.4)$ & $93(68.6)$ & $0.48(0.26-0.88)$ & $<0.01$ \\
\hline- & After meal & $21(28)$ & $98(72)$ & $0.31(0.17-0.56)$ & $<0.0001$ \\
\hline- & After toilet & $22(28.9)$ & $97(71.1)$ & $0.42(0.23-0.79)$ & $<0.006$ \\
\hline
\end{tabular}


Table 3. Epidemiological factors influencing acquisition of $\mathrm{Hp}$ infection.

\begin{tabular}{cccccc}
\hline \multicolumn{7}{c}{ Fecal Hp Ag test result } & & & \\
\hline Explanatory variables & $\begin{array}{c}\text { Positive } \\
(\mathrm{n}=46 ; \%)\end{array}$ & $\begin{array}{c}\text { Negative } \\
(\mathrm{n}=60 ; \%)\end{array}$ & $\begin{array}{c}\text { OR } \\
(\text { IC-95\%) }\end{array}$ & $\begin{array}{c}\text { Chi } \\
\text { square }\end{array}$ & p \\
\hline Age: 5 - 9 years & $18(45)$ & $22(55)$ & $0.61[0.22-1.78]$ & 2.8 & 0.04 \\
Primary education level & $22(41.2)$ & $21(58.5)$ & $0.35[0.12-1.09]$ & 6.4 & 0.01 \\
Guardian age: 35 - 44 years & $22(52.4)$ & $20(47.6)$ & $1.22[0.42-3.62]$ & 3.5 & 0.03 \\
Type of toilet (chamber pot) & $38(44.2)$ & $48(55.8)$ & $2.37[0.61-9.38]$ & 2.8 & 0.02 \\
$\quad$ Hand washing & & & & & \\
$-\quad$ Before meal & $12(66.7)$ & $6(33.3)$ & 1 & 4.7 & 1 \\
- After meal & $9(69.2)$ & $4(30.8)$ & 1 & 4.02 & 0.04 \\
- After toilet & $26(56.5)$ & $20(43.5)$ & 1 & 5.7 & 0.01 \\
\hline
\end{tabular}

Table 4. Impact of $H p$ infection in RAP.

\begin{tabular}{ccccc}
\hline \multicolumn{5}{c}{ Fecal Hp Ag test result } \\
Population & number & $\begin{array}{c}\text { Positive } \\
(\mathbf{n} ; \%)\end{array}$ & $\begin{array}{c}\text { Negative } \\
(\mathbf{n} ; \%)\end{array}$ & $\mathrm{p}$ \\
\hline Case & 106 & $46(43.4)$ & $60(56.6)$ & 0.10 \\
control & 212 & $76(35.5)$ & $136(64.2)$ & \\
\hline
\end{tabular}

\section{Discussion}

We report the results of a comparative cross-sectional study on the role of $\mathrm{Hp}$ infection in the occurrence of RAP in infected children in Brazzaville; on two series of children, the first with RAP and the second without RAP. Based on the hypothesis that in Congo, precariousness would be a predictive factor and that RAP would be due to high Hp infestation. The inclusion criteria were sufficiently clear to avoid bias in the interpretation of the results. However, this study has limitations; on the one hand, this survey limited only to urban areas should be considered as preliminary work. As the survey was cross-sectional, it was not possible to estimate the temporal sequence between $\mathrm{Hp}$ and RAP, and therefore it did not allow a direct estimation of the risk. On the other hand, we admit a selection bias because participation in the study was on a voluntary basis and the RAPs were not a frequent reason for consultation during our study period.

The prevalence of Hp infection in children with RAP is $43.4 \%$. Our result is similar to those of Franck and coll. in Switzerland [14] and Masoodpoor and coll. in Iran [15] who reported $40 \%$ each. However, it is lower than that of Sebanjo and coll. in Nigeria, 63.6\% [16]. However, Kumar and Mohsen and coll. reported lower prevalences [17] [18]. This discrepancy could be explained by methodological differences in sampling, ethnic and environmental factors, and the method of detection of $\mathrm{Hp} \mathrm{Ag}$. Comparison between the two types of populations revealed similarities in age, gender, education and age of guardian. Indeed, children between the ages of 5 and 9 years were the most infected with a 
mean age of $8.13 \pm 4.57$ years. The relationship between age and Hp infection was statistically significant $(\mathrm{p}<0.05)$. Our result is superimposable to that of Alimohammadi and coll. in Iran [19] and Punhal et al. in Pakistan [20]. However Ozen et al. in Turkey [21] and Masoodpoor [15] report a higher mean age probably due to the difference in the selected age groups and the sample size. The majority of infected children were not attending school, with a predominance of cases $(66.7 \%)$ compared to $53.8 \%$ of controls. Our results could be explained by the fact that the unschooled children were in the under- 5 age group. We found a significant relationship between $\mathrm{Hp}$ and education level. Children with young guardians were the most infected in our study. Our results could be explained by the inexperience and/or unavailability of young parents in the education of the children. However, Ategbo et al. in Gabon did not find a statistical correlation between $\mathrm{Hp}$ and age of the guardian [6]. Children using latrines and especially chamber pots were the most infected in both study populations with a statistically significant association ( $\mathrm{OR}=2.37$; $<0.02$ ). Etukudo et al. in Nigeria made the same observation [22]. This result, which can be superimposable on our own, can be explained by the precariousness of households in some African countries. Similarly, both in the case and control populations, children using public tap water were more infected with $\mathrm{Hp}$. However, no significant difference was observed between $\mathrm{Hp}$ and the water source ( $\mathrm{p}>0.005)$. Nevertheless, the association between $\mathrm{Hp}$ infection and hand washing before, after meals and after toilet use was statistically significant (Table 3 ). These results could be explained by the poor hygiene and living conditions of the Congolese population as reported by the Congo Demographic and Health Survey report [23]. Epigastric pain was prevalent among infected children with ARD. The association between $\mathrm{Hp}$ infection and the site of pain was statically significant $(\mathrm{p}<0.005)$. Our finding is superimposable to that of Senbanjo. This is due to the gastric tropism of the bacterium. Moreover, the existence of epigastralgia would be the only symptom of pseudo-ulcer dyspepsia, which is poorly appreciated in young children who express themselves poorly. Vomiting was the only symptom with a statistically significant association with Hp infection $(\mathrm{p}<0.05)$. Vomiting would be a predictor of gastrooral contamination in our country.

Logistic regression found that the epidemiological factors favouring the acquisition of $\mathrm{Hp}$ infection in children were identical in the two types of populations; namely, age between 5 and 9 years of age, level of education of the children, age of the guardian between 35 and 44 years of age, type of toilet and lack of handwashing. The major predictive factor with higher risk in children was the use of chamber pots $(\mathrm{OR}=2.37 ; \mathrm{p}=0.02)$. We observe a similarity of results with those of Senbanjo and Shaker et al. in India regarding age [16] [24]. The diversity observed for the other factors could be justified by the choice of variables in each of these studies.

The authors' opinions are still controversial on the existence of a close relationship between RAPs and Hp [14] [25]. The bivariate analysis between cases and controls did not reveal a statistical association between $\mathrm{Hp}$ infection and 
RAPs with respect to the required significance level, although the association was real in $10 \%$ of cases $(p>0.05)$. Our results are consistent with those of many studies [15] [26] [27]. However, other authors have found a correlation between Hp and RAP [18] [19] [21] [24]. This difference could be justified by the type of cross-sectional study that did not allow to estimate the temporal sequence between Hp and RAP i.e. whether the factors studied preceded the infection or vice versa, the small sample size, the method of detection of Hp infection and the surrounding factors. Our results suggest that the presence of Hp infection in RAPs should be an argument for the "test and treat" strategy because of the high frequency of this infection in developing countries.

\section{Conclusion}

Hp infection is common among children with RAP in Brazzaville. It is favoured by young age and lack of hygiene. The cause-effect relationship between Hp and RAP has not been found, although it is real in $10 \%$ of cases. Nevertheless, the search for Hp faecal antigen in children with RAP should be recommended in order to improve the management of this pathology and to prevent complications related to $\mathrm{Hp}$ infection in young persons.

\section{Conflicts of Interest}

The authors declare no conflicts of interest with respect to the publication of this article.

\section{References}

[1] De Korwin, J.D. and Lehours, P. (2010) Helicobacter pylori: Fundamentals Notions, Epidemiology, Diagnosis Methods. EMC-Gastro-entérologie, 27, 1-16. https://doi.org/10.1016/S1155-1968(10)50083-X

[2] Bommelaer, G. and Stef, A. (2009) Gastroduodenal Ulcer: Before and after Helicobacter pylori. Gastroentérologie Clinique et Biologique, 33, 626-634. https://doi.org/10.1016/j.gcb.2009.07.004

[3] De Korwin, J.D. (2014) Epidemiology of Helicobacter pylori Infection and Gastric Cancer. La Revue du Praticien, 64, 189-193.

[4] Hunt, R.H., Xiao, S.D., Megraud, F., Leon-Barua, R., Bazzoli, F., Van Der Merwe, S., et al. (2011) Helicobacter pylori in Developing Countries. World Gastroenterology Organisation Global Guideline. Journal of Gastrointestinal and Liver Diseases, 20, 299-304.

[5] Benallal, K. (2008) Prevalence Helicobacter pylori Infection in the Child and Adolescent of West Algerian. Archives of Pediatrics, 15, 945-946. https://doi.org/10.1016/S0929-693X(08)72138-9

[6] Ategbo, S., Minto'o Rogombe, S., Ngoungou, E.B., Midili, T.L. and Moussavou, A. (2013) Epidemiology of Helicobacter pylori Infection in Children of 6 Months to 7 Years at Libreville, Gabon. Clinics in Mother and Child Health, 10, 1-5.

[7] Awuku, Y.A., Simpong, D.L., Alhassan, I.K., Tuoyire, D.A., Afaa, T. and Adu, P. (2017) Prevalence of Helicobacter pylori Infection among Children Living in a Rural Setting in Sub-Saharan African. BMC Public Health, 17, Article No. 360. 
https://doi.org/10.1186/s12889-017-4274-Z

[8] Ibara, J.R., Mbou, V.A., Gatsele-Yala, C., Ngoma-Mambouana, P., Ngounga, B. and Yala, F. (2005) Infection of Helicobacter pylori in Children of 6 Months to 16 Years in Brazzaville. Gastroentérologie Clinique et Biologique, 6-7, 752-753.

https://doi.org/10.1016/S0399-8320(05)82170-0

[9] Zamani, M., Vahedi, A., Maghdouri, Z. and Shokri-Shirvani, J. (2017) Role of Food in Environmental Transmission of Helicobacter pylori. Caspian Journal of Internal Medicine, 8, 146-152.

[10] Kalach, N., Gosset, P., Dehecq, E., Decoster, A., Papado polo, S., Spyckerelle, C., et al. (2016) Antigen Rapid Test in Stools during Helicobacter pylori Infection Diagnosis in Pediatric. Archives of Pediatrics, 23, 1295-1304.

[11] Boukthir, S. and Mazigh, S. (2005) Evaluation of a Non Invasif Test in the Detection of Helicobacter pylori Antigens in Stools of Children. Archives of Pediatrics, 12, 82-87. https://doi.org/10.1016/j.arcped.2004.10.018

[12] Gottrand, F. (2000) Place of Helicobacter pylori in Abdominal Pain of the Child. Archives of Pediatrics, 7, 197-200. https://doi.org/10.1016/S0929-693X(00)88091-4

[13] Bode, G., Rothenbacher, D., Brenner, H. and Alder, G. (1998) Helicobacter pylori and Abdominal Symptoms: A Population-Based Study among Preschool Children in Southern Germany. Pediatrics, 101, 634-637.

https://doi.org/10.1542/peds.101.4.634

[14] Frank, F., Stricker, T., Stallmach, T. and Braegger, C.P. (2000) Helicobacter pylori Infection in Recurrent Abdominal Pain. Journal of Pediatric Gastroenterology and Nutrition, 31, 424-427. https://doi.org/10.1097/00005176-200010000-00017

[15] Masoodpoor, N., Darakhshan and Sheikhvatan, M. (2008) Helicobacter pylori Infection in Iranian Children with Recurrent Abdominal Pain. Tropical Gastroenterology, 29, 221-223.

[16] Senbanjo, I.O., Oshikoya, K.A. and Njokanma, O.F. (2014) Helicobacter pylori Associated with Breastfeeding, Nutritional Status and Recurrent Abdominal Pain in Healthy Nigerian Children. Journal of Infection in Developing Countries, 8, 448-453. https://doi.org/10.3855/jidc.3196

[17] Kumar, D. and Vidyarthi, U.C. (2018) Helicobacter pylori Infection in Recurrent Abdominal Pain in Children. International Journal of Medical and Health Research, 4, 148-150.

[18] Mohsen, A.A.H., Manji, A.J., Hashim, J.M. and Obeid, R.M. (2018) The Significance of Helicobacter pylori Infection as a Cause of Recurrent Abdominal Pain in Children. Current Pediatric Research, 22, 82-87.

[19] Alimohammadi, H., Fouladi, N., Salehzadeh, Alipour, S.A. and Javadi, M.S. (2016) Childhood Recurrent Abdominal Pain and Helicobacter pylori Infection, Islamic Republic of Iran. Eastern Mediterranean Health Journal, 22, 860-864. https://doi.org/10.26719/2016.22.12.860

[20] Punhal, M., Malik, Q. and Iqbal, A. (2016) Helicobacter pylori Infection in Children Presenting with Recurrent Abdominal Pain. Pakistan Armed Forces Medical Journal, 66, 266-269.

[21] Özen, H., Dinler, G., Akyön, Y., Koçak, N., Yüce, A. and Gürakan, F. (2001) Helicobacter pylori Infection and Recurrent Abdominal Pain in Turkish Children. $\mathrm{He}$ licobacter, 6, 234-238. https://doi.org/10.1046/j.1523-5378.2001.00033.x

[22] Etukudo, O.M., Ikpeme, E.E. and Ekanem, E.E. (2012) Seroepidemiology of Helicobacter pylori Infection among Children Seen in a Tertiary Hospital in Uyo, 
Southern Nigeria. The Pan African Medical Journal, 12, 39.

https://doi.org/10.4314/njp.v40i1.8

[23] Ministère du Plan, de l'Aménagement, du Territoire, de l'Intégration Economique et du NEPAD, Centre National de la Statistique et des Etudes Economiques (2012) Demographic and Health Survey in Congo (EDSC-II).

[24] Shaker, K. (2011) Helicobacter pylori Positivity in Children with Recurrent Abdominal Pain and Possible Risk Factors. Kufa Medical Journal, 14, 78-84.

[25] Benallal, K., Bouziane-Nedjadi, K., Hachelaf, W., Makhloufi, S., Bentaallah, A., Boudraa, G., et al. (2010) Role of $H$. pylori Infection in Children with Recurrent Abdominal Pain. Archives of Pediatrics, 16, 61.

https://doi.org/10.1016/S0929-693X(10)70443-7

[26] Silva Correa, R.G.S., Machado, N.C., Carvalho, M.A. and Rodrigues, M.A.M. (2016) Helicobacter pylori Infection Is High in Paediatric Nonulcer Dyspepsia but Not Associated with Specific Gastrointestinal Symptoms. Acta Paediatrica, 105, 228-231. https://doi.org/10.1111/apa.13347

[27] Daugule, I., Rumba, I., Alksnis, J. and Ejderhamn, J. (2007) Helicobacter pylori Infection among Children with Gastrointestinal Symptoms: A High Prevalence of Infection among Patients with Reflux Oesophagitis. Acta Paediatrica, 96, 1047-1049. https://doi.org/10.1111/j.1651-2227.2007.00329.x 


\section{Survey Sheet}

Role of helicobacter pylori infection in recurring abdominal pain in children in Brazzaville

Date of investigation: |_______ _ _ _ $\mathbf{N}^{\circ}$ of sheet: |_ _ _ _

Hospitalized patient:

Patient seen in consultation:

1) Epidémiological parameters

- Sex:

$\mathrm{M}$

$\mathrm{W}$

- Date of birth: |___________ et/ou Age: ans

- School level:

Préschool

Primary

Secondary

Unschooled

Others

- Dwelling place:

- Child custody:

Mother father

Grand-mother

- Age of primary guardian.

- Number of people living under the same roof: |___

2) Habits (multiple answers possible)

- Type of latrine:

Modern

Traditionnal

Public

Private

Both

- Water source:

Public tap

Spring water

Modern wells

Private faucet

- Other sources to be specified:

- Hand washing:

Meal: Before

Toilet: Before

After

3) Clinical parameters (Several answers possible)

a) Antecedent

i) personnal

- Gastric ulcer: 
Yes

No

Without precision

- Duodenal ulcer:

Yes

No

Without precision

- Gastric cancer:

Yes

No

Without precision

- Others to be specifised: .....

ii) Family

- Gastricand/or duodenal:

Yes

No

- Gastric:

Yes

No

b) Digestive symptoms

- Pain type:

Burning

Cramping

Compression

- Site of pain:

Epigastrium

Right hypochondrium

Diffuse

Left hypochondrium

Others to specify.

- Nausea

Yes

No

- Early feeling of fullness

Yes

No

- Sensation of gastric fullness

Yes

No

- Belching

Yes

No

- Pyrosis

Yes 
No

- Regurgitation

Yes

No

- Vomiting

Yes

No

- Haematemesis

Yes

No

- Melena

Yes

No

- Other digestive symptoms to be specified..........................

4) Biological parameters

- Results of the test for the detection of Ag H. pylori in the stool:

Positive

Negative 